\title{
The extraction of fossil arthropods from Lower Eocene Cambay amber
}

Nina Mazur, Michael Nagel, Ulrich Leppin, Gabriele Bierbaum, and Jes Rust

Acta Palaeontologica Polonica 59 (2), 2014: 455-459 doi: http://dx.doi.org/10.4202/app.2012.0018

Fossil arthropods preserved in amber typically comprise only hollow spaces lined with a thin layer of diagenetically altered or decomposed cuticle. In contrast, the cuticle of inclusions from Lower Eocene Cambay amber (Gujarat, India) is commonly perfectly preserved and moreover allows the extraction of whole specimens. Here we report on the examination of several groups of solvents to determine their ability to dissolve Cambay amber. The amber dissolves well in toluene, xylene, dichloromethane and trichlormethane (chloroform). Even orange oil and turpentine oil dissolve Cambay amber quite well. The extraction of inclusions by dissolving the amber matrix enables various novel observations and further investigations with biological analytical methods, although the material is extremely fragile after extraction.

Nina Mazur [mazur@uni-bonn.de] and Jes Rust [jrust@uni-bonn.de], Steinmann Institute of Geology, Mineralogy and Palaeontology, University of Bonn, Nußallee 8, D-53115 Bonn, Germany; Michael Nagel [nagel.mf@gmail.com], Gabriele Bierbaum [bierbaum@mibi03.meb.unibonn.de] and Ulrich Leppin, Institute of Medical Microbiology, Immunology and Parasitology, University of Bonn, Sigmund-Freud-Str. 25, 53105 Bonn, Germany.

This is an open-access article distributed under the terms of the Creative Commons Attribution License (for details please see creativecommons.org), which permits unrestricted use, distribution, and reproduction in any medium, provided the original author and source are credited. 